\title{
MAPPING OF CODA ATTENUATION AT THE EXTEND OF THE NATIONAL SEISMOLOGICAL NETWORK OF GREECE
}

\author{
Baskoutas I. ${ }^{1}$, Herraiz M. ${ }^{2}$, Pérez A.C. ${ }^{2}$, Kalogeras I. ${ }^{1}$, Panopoulou G. ${ }^{1}$, Sachpazi M. ${ }^{1}$ \\ and Papadopoulos $\mathrm{G}^{3}$ \\ ${ }^{1}$ National Observatory of Athens, P.O.Box 2004811810 Athens i.basko@.gein.noa.gr, \\ ${ }^{2}$ Dep. de Geofisica y Meteorologia, Universidad Complutense de Madrid, 28040, Madrid, \\ mherraiz@fis.ucm.es \\ ${ }^{3}$ Earthquake Planning and Protection Organization, Seismotectonic Div., Xanthou32, \\ 15451 Athens
}

\begin{abstract}
Coda decay rates of 538 vertical components corresponding to local earthquakes which occurred in Greece during the period 1998 to 1999 were used to deduce the coda quality factor $\left(\mathrm{Q}_{c}\right)$ characteristics in the Hellenic area. The seismograms have been selected from a broader sample of 776 records obtained at 8 stations of the National Seismographic Network operated by the Institute of Geodynamics of the National Observatory of Athens. Earthquake magnitudes range from 2.5 to 4.0; epicentral distances and depths are smaller than $100 \mathrm{~km}$ and $40 \mathrm{~km}$, respectively. Using the Single Back Scattering model, the dependence of $Q_{c}$ on frequencies between 1 and $10 \mathrm{~Hz}$ has been investigated at each station and the usual $Q_{c}=Q_{0} f^{n}$ relationships have been deduced. The spatial distribution of $Q_{0}$ has been drawn using waves that sample approximately equivalent ellipsoidal volumes with semiminor axis up to $100 \mathrm{~km}$. The corresponding map shows a decreasing trend in S$\mathrm{N}$ direction.
\end{abstract}

\section{INTRODUCTION}

In spite of their theoretical limitations, the analysis of waves of coda has been considered an effective method to estimate quality factor of seismic wave attenuation. Nevertheless, the influence of some analysis parameters like length of the time window and selection of the beginning of coda, affects the results.

In this sense obtained values are not easy to compare even within the same territory.

Besides that, results for most of territories concerns limited extent of areas or lack of uniform seismological data. To overcome such a difficulty, the spatial distribution of $Q$ in an extensive zone can be obtained by applying the same methodology to a uniform set of data in the extent of dense national seismological network.

Modern instrumentation offers the possibility to analyze the spatial distribution of $Q c$ ( $Q$ factor considered from waves coda) in the Greek territory, area for which numerous studies exists (see APPENDIX table, from Panagiotopoulos et al., 1998., competed by the authors) but, nevertheless, in zones of small size, usually covered from locally operating seismological networks, for which the temporarily character doesn't permit any future comparison. (Martin, 1988, Tselentis et., al., 1988, Baskoutas et., al., 1989 ; 1992 ; 1993; 1995; Hatzidimitriou, 1993; 1995; Baskoutas, 1996; 1998; Tselentis, 1997).

Single Back-Scattering model has been chosen to be used in the present study because it facilitates the comparison with other studies made in different zones within Greek territory and elsewhere.

In order to obtain the spatial distribution of Qc values, data with good azimuthal distribution are selected to cover homogeneously the space around the seismological stations. 
Tests have been made by running both the CODAQ Havskov's (1989) and Baskoutas software (1993) as well as the Single Isotropic scattering model (Sato, 1977a,b) at a representative set of data. No significant differences have been noticed.

\section{DATA}

We used 538 earthquakes which occurred in the period 1998 to 1999 and were recorded by eight seismological stations of the National Seismic Network of Greece.

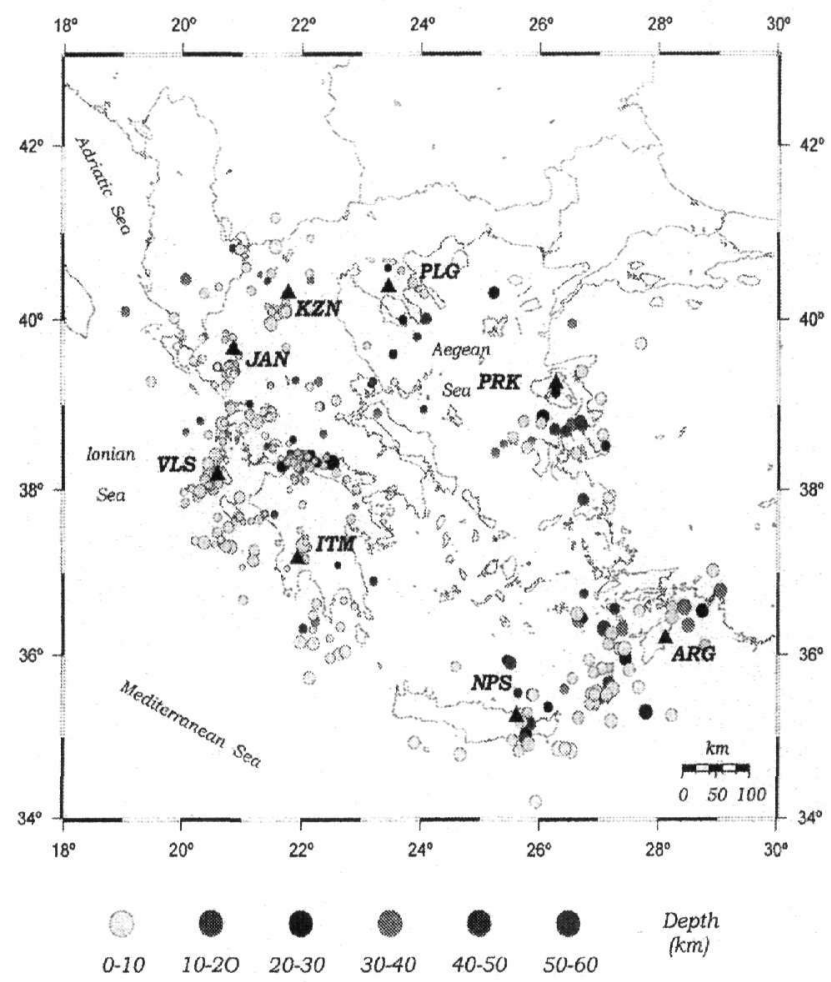

Figure 1 Epicenters map (The locations of the stations is shown by triangles).

A first set of 776 earthquakes were obtained from vertical components at eight stations of the National Seismic Network of Greece. Magnitudes are between 2,5 and 4,0. Hypocenter depths and epicenter distances are less than $40 \mathrm{~km}$ and $100 \mathrm{~km}$ respectively (Figure 1). All events were recorded by broadband seismometers of three components. In both cases the sampling frequency is 50 sample/sec. Seismograms were inspected visually for errors (i.e. noise contamination and location parameters). Therefore some of them have been rejected and a total of 538 events have been selected (Table 1).

Table 1. Stations and number of events.

\begin{tabular}{ll}
\hline Station Name & $N^{\circ}$ of Events \\
\hline ARG & 55 \\
ITM & 74 \\
JAN & 53 \\
JAN & 63 \\
KZN & 45 \\
PLG & 51 \\
PRK & 79 \\
VLS & 118 \\
\hline
\end{tabular}


The noise level was evaluated considering the average value of the spectrum amplitude corresponding to 10 second before the arrival time of $\mathrm{P}$-wave. $\mathrm{S}$ wave arrival was identified on the horizontal components.

\section{ANALYSIS AND RESULTS}

As a first step we studied at each station, the variation of $Q$ value for six different parameter sets resulting from combinations between chosen time window and coda onsets i.e. considering three different length of time window $(10,20$ and $30 \mathrm{~s})$ and two coda waves origin time $(t=1.5 \mathrm{ts}$ and $\mathrm{t}=2 \mathrm{ts}$ ). The analysis was carried out using the model of Single Back-Scattering (Aki and Chouet, 1975). Signals are filtered by the mean of band-pass filter with center frequencies at 1.5, 3, 5,7 and $9 \mathrm{~Hz}$. Analysis has shown that the most stable results were obtained, using as coda wave origin time the value of $2 \mathrm{ts}$ and a length of lapse time window $20 \mathrm{sec}$. (Perez, 2000). Table 2 shows the results for $Q_{0}$ for entire coda length (value of $Q_{c}$ at $1 \mathrm{~Hz}$ ) and $n$ corresponding to the power low relation for each station.

$$
Q_{c}=Q_{0} f^{n}
$$

For $Q_{0}$ the spatial distribution of the common sampling volumes for each event was considered. This volume depends on the lapse time interval $t$. In this way scatterers that take part in the process of coda waves generation, are located, in a volume of an expanding elipsoid, with foci the station and the source (Pulli, 1984).

$$
\frac{x^{2}}{\left(v_{s} t / 2\right)^{2}}+\frac{y^{2}}{\left(v_{s} t / 2\right)^{2}-R^{2} / 4}=1
$$

In the relation (2) Vs is the shear wave velocity, $t$ is the travel time interval and $R$ is the sourcestation distance. The semiaxis $a_{1}$ and $a_{2}$ are equal to $\left(v_{s} t / 2\right)^{2}$ and $a_{1}{ }^{2}-R^{2} / 4$ respectively.

Examined ellipsoids can be practically considered spherical $\left(a_{1} / a_{2} \approx 1\right)$ thus maximum depth can be defined as $z_{\max }=a_{2}+h$, where $h$ is the depth of the earthquake (Havskov et., al., 1989). S wave velocities with respect to the depth are considered as follow:

$\mathrm{h} \leq 15 \mathrm{~km} \Rightarrow \mathrm{v}_{\mathrm{s}}=3.47 \mathrm{~km} / \mathrm{s}$

$15<\mathrm{h} \leq 40 \mathrm{~km} \Rightarrow \mathrm{v}_{\mathrm{s}}=3.90 \mathrm{~km} / \mathrm{s}$,

which correspond to the regional velocity model, used by the Geodynamic Institute of National Observatory of Athens, for the earthquake location.

For the analysis two restrictions were adopted. First, the dimension of the sampling volume, which should mostly correspond to the crust and second, having at the same time a sufficient number of events to be processed, which guarantees for the results significance. The optimal value between these two conditions was $a_{2} \leq 100 \mathrm{~km}$. Although the number of earthquakes for each station (values between parenthesis in Table 3) in some cases, was reduced drastically, still it can be considered sufficient for the study. Figures 2 and 3 shows $Q 0$ and $n$ values, for different ellipsoid semi axis values $(100,130,160 \mathrm{Km})$ at each station of the Seismological network. Open circles stand for $a_{2}=100 \mathrm{Km}$, full rectangles and triangles for 130 and $160 \mathrm{Km}$, respectively. The clear difference of $Q_{0}$ values among the group of stations situated in the concave part of the island arc (JAN KZN, PLG, PRK), and those situated in the convex part (ARG, ITM, NPSM and VLS), can bee seen in figure 2 . 
Table 2. $\mathbf{Q}_{0}$ and $\mathbf{n}$ values

\begin{tabular}{lrr}
\hline Station & $\mathrm{Q}_{0}$ & $\mathrm{n}$ \\
\hline ARG & $83 \pm 1$ & $0.89 \pm 8 \mathrm{e} 2$ \\
ITM & $99 \pm 8$ & $0.63 \pm 5 \mathrm{e}-2$ \\
JAN & $67 \pm 4$ & $0.71 \pm 5 \mathrm{e}-2$ \\
KZN & $67 \pm 9$ & $0.63 \pm 9 \mathrm{e}-2$ \\
NPS & $76 \pm 2$ & $0.89 \pm 2 \mathrm{e}-2$ \\
PLG & $71 \pm 5$ & $0.73 \pm 6 \mathrm{e}-2$ \\
PRK & $91 \pm 8$ & $0.80 \pm 6 \mathrm{e}-2$ \\
VLS & $78 \pm 2$ & $0.82 \pm 2 \mathrm{e}-2$ \\
\hline
\end{tabular}

Table 3. $Q_{0}$ and $n$ values for different values of $a_{2}$ parameter

\begin{tabular}{|c|c|c|c|c|c|c|c|c|c|}
\hline Station & $Q_{0}$ & $n$ & $\begin{array}{l}\text { No of } \\
\text { cases }\end{array}$ & $Q_{0}$ & $n$ & $\begin{array}{l}\text { No of } \\
\text { cases }\end{array}$ & $Q_{0}$ & $\mathrm{n}$ & $\begin{array}{l}\text { No of } \\
\text { cases }\end{array}$ \\
\hline & \multicolumn{3}{|c|}{$\left(a_{2} \leq 100 \mathrm{~km}\right)$} & \multicolumn{3}{|c|}{$\left(a_{2} \leq 130 \mathrm{~km}\right)$} & \multicolumn{3}{|c|}{$\left(a_{2} \leq 160 \mathrm{~km}\right)$} \\
\hline ARG & $77 \pm 12$ & $0.84 \pm 7 E-2$ & (4) & $77 \pm 6$ & $0.89 \pm 6 \mathrm{E}-2$ & (21) & $71 \pm 5$ & $0.945 \pm 1 E-3$ & (41) \\
\hline ITM & $71 \pm 10$ & $0.644 \pm 1 E-3$ & (9) & $83 \pm 7$ & $0.64 \pm 7 E-2$ & (24) & $92 \pm 7$ & $0.63 \pm 4 E-2$ & (48) \\
\hline JAN & $59 \pm 3$ & $0.71 \pm 5 E-2$ & (31) & $59 \pm 3$ & $0.75 \pm 5 \mathrm{E}-2$ & (42) & $63 \pm 4$ & $0.74 \pm 5 E-2$ & (47) \\
\hline$K Z N$ & $59 \pm 7$ & $0.68 \pm 7 \mathrm{E}-2$ & (19) & $59 \pm 7$ & $0.68 \pm 7 \mathrm{E}-2$ & (21) & $63 \pm 8$ & $0.67 \pm 8 \mathrm{E}-2$ & (34) \\
\hline NPS & $69 \pm 4$ & $0.77 \pm 3 E-2$ & (12) & $71 \pm 5$ & $0.87 \pm 5 E-2$ & (23) & $72 \pm 3$ & $0.90 \pm 3 E-2$ & (36) \\
\hline PLG & $60 \pm 2$ & $0.77 \pm 2 E-2$ & (14) & $63 \pm 1$ & $0.760 \pm 9 E-3$ & (25) & $71 \pm 5$ & $0.74 \pm 5 E-2$ & (38) \\
\hline PRK & $59 \pm 7$ & $0.91 \pm 8 E-2$ & (12) & $82 \pm 5$ & $0.81 \pm 4 E-2$ & (31) & $87 \pm 6$ & $0.79 \pm 4 \mathrm{E}-2$ & (42) \\
\hline VLS & $76 \pm 3$ & $0.68 \pm 2 E-2$ & (21) & $76 \pm 2$ & $0.78 \pm 1 E-2$ & (42) & $79 \pm 3$ & $0.79 \pm 2 E-2$ & (75) \\
\hline
\end{tabular}

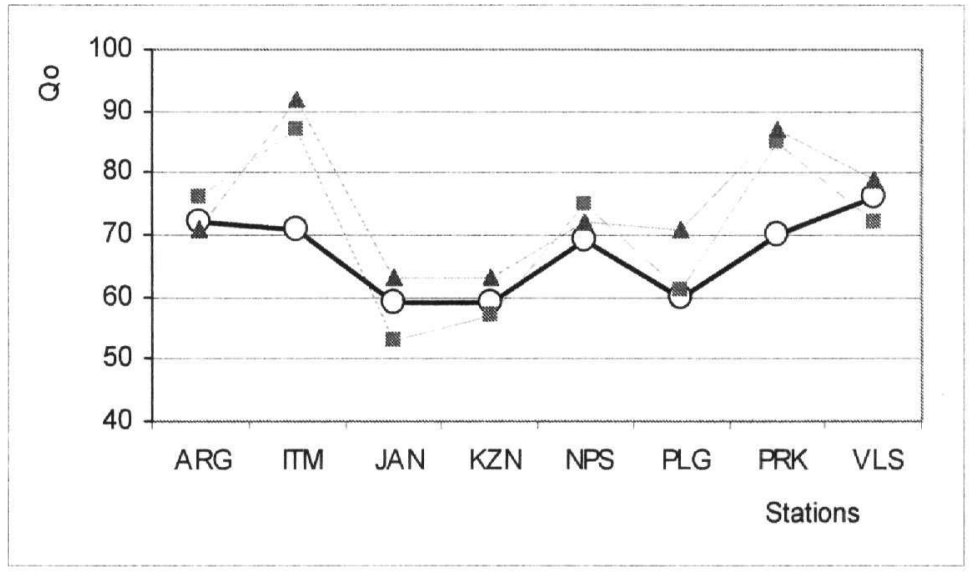

Figure 2. Qo at the NOA seismic stations for different ellipsoid semi axis values $\left(a_{2}=100 \mathrm{Km}\right.$, open circles). Full rectangles and triangles represents the Qo values for $\mathrm{a}_{2}$ equal to 130 and $160 \mathrm{Km}$ respectively. 


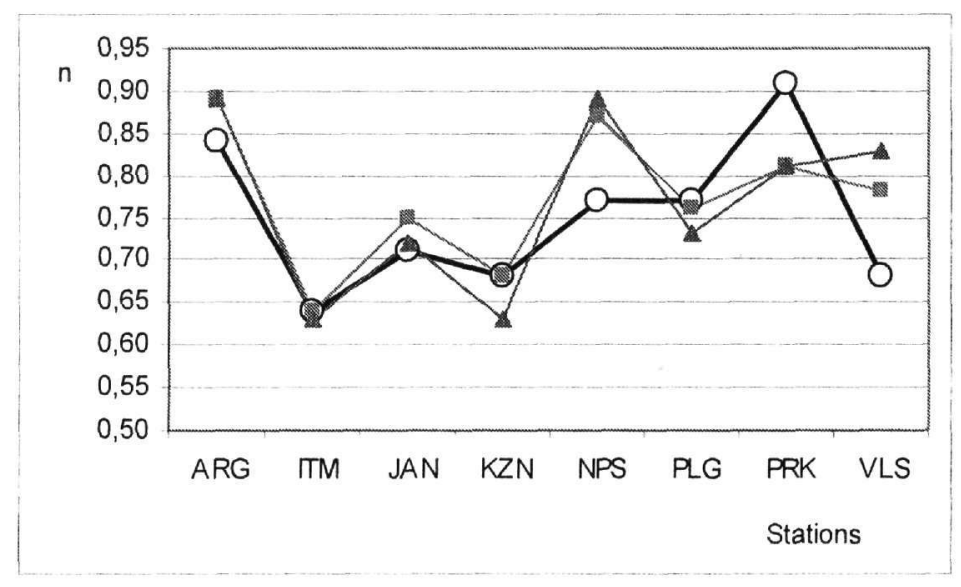

Figure 3. $n$ values at the NOA seismic station for different ellipsoid semi axis values, $\left(a_{2}=100 \mathrm{Km}\right.$, open circles) Full rectangles and triangles represents the $Q 0$ values for $\mathrm{a}_{2}$ equal to 130 and $160 \mathrm{Km}$ respectively.

\section{DISCUSSION AND CONCLUSIONS}

The obtained results show that the Hellenic region is characterized by a high seismic attenuation. $Q$ values of the table 2 , summarizes the data obtained for all earthıquakes in each station without considering any restrictions for the sampling volume. These results are, in general, coherent with those obtained in previous studies, when the comparison is possible. Thus, Hatzidimitriou (1993), using a time window of 15-30s, has obtained, for north Greece, $Q_{0}=60$ and $n$ $=0,79$ that is very similar to the results of this work for PLG station. The similarity increases when $a_{2}=100 \mathrm{Km}$ is considered.

In the case of Kozani station also coherence exists, within the margin of error, with the results of Baskoutas et., al., (1998) for the window of 20s. Instead, for Peloponnesus area and for unknown length of time window, Martin (1988) reports $Q_{0}=73$ and $n=0,79$, that differs from the results of this work at ITM station, located in the western part of the zone. In several cases comparison with results of other authors is not easy, because of missing information or of different parameters set used for the data analysis.

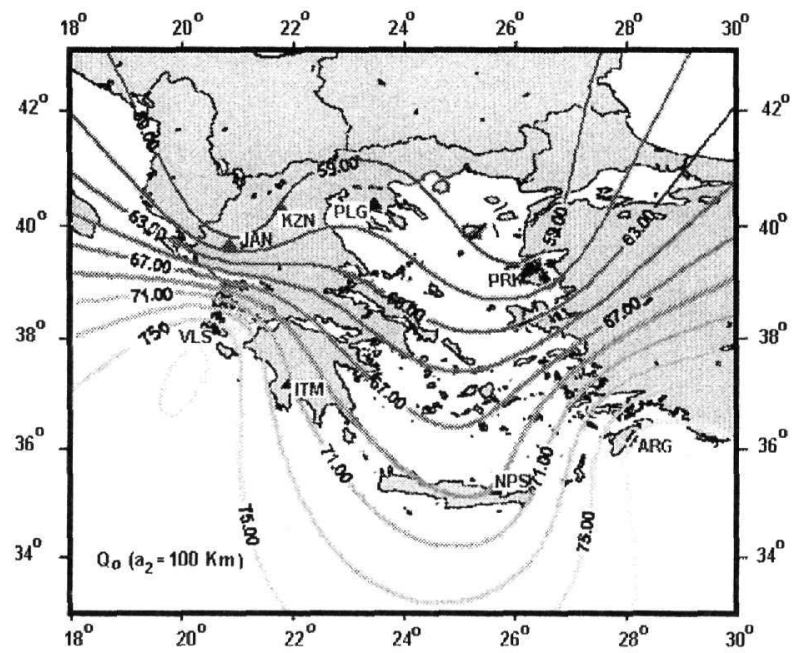

Figure 5. Spatial distribution of $Q 0$ for $a_{2} \leq 100 \mathrm{~km}$ 


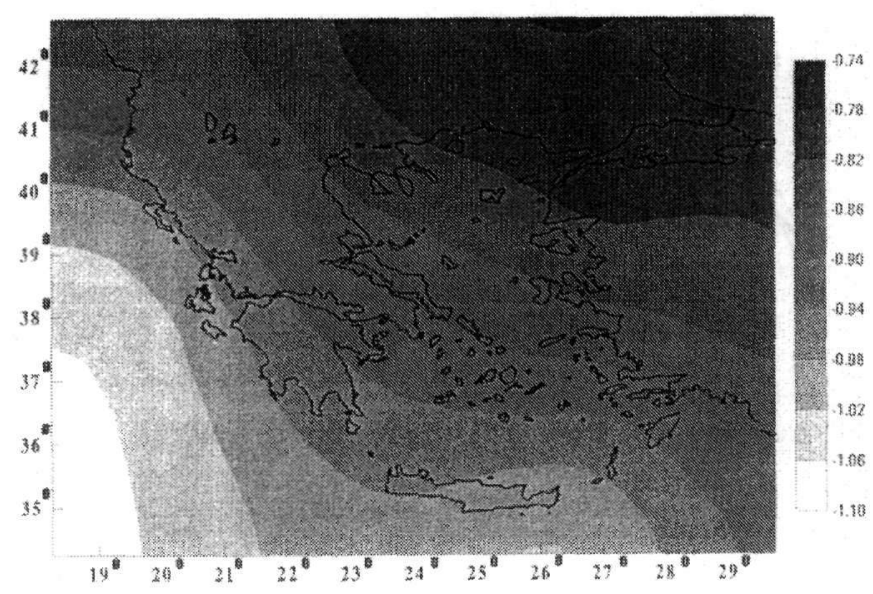

Figure 6. Spatial variation of b value from superficial seismic activity, (Papazachos and Papazachou 1997).

Obtained spatial variation for $a_{2} \leq 100 \mathrm{~km}$ (Figure 5) shows a significant attenuation characteristic for Greek terittory, and indicates that attenuation in the concave zone is larger that in the convex one.

In figure 5, also, a sharp Qo variation in the Ioanian Sea islands is observed with a slight increase towards the N-S direction. This area is characterized by high seismic activity and is influenced by different tectonic regimes. It is also important to notice that this tendency keeps a remarkable similarity with the spatial variation (Figure 6) of $b$ value given by Papazachos and Papazachou (1997) for shallow seismic activity. Tendency indicating that $b$ value decrease in a systematic way from the southwest to the northeast. This result indicates that the values of $Q_{c}$ tend to diminish in the zones in which the geological formation age is older (Baskoutas et al., 2000).

All the values assigned to the semiaxis $a_{2}$ imply that the sampling volume comprises also part of the upper mantle playing an important role to the increase of $Q_{c}$ values, the contribution of the crust must be very small. In order to confirm the above statement, it is necessary to diminish axis $a_{2}$ (and thus the upper mantle contribution) using higher number of events.

Although the differences are small, the comparison of the results obtained for different values of the sampling volume (Table 3 ) confirms the increase of $Q_{0}$ as depth increases.

\section{ACKNOWLEDGEMENTS}

This work has been carried out within the frame of the bilateral scientific and technological collaboration between Greece and Spain 1996-1998, supported by the General Secretary of Research and Technology, Greece (code number 7557/09-07-1997).

\section{REFERENCES}

Aki,K. \& Chouet B. 1975. Origin of coda waves: source, attenuation, \& scattering effects. Journal of Geophysical Research, 80, 23, 3322-3342.

Baskoutas I. 1993. Contribution on the study of the attenuation of seismic coda in central Greece. Ph.D Thesis, University of Athens, 246pp.

Baskoutas I., Makropoulos K. \& Sato H. 1995. Mean free path for S-wave scattering under central Greece. Boll. di Geof. Teor. ed Appl., 145, 73-80.

Baskoutas I. 1996. Dependence of coda attenuation on frequency and lapse time in central Greece". Pure Appl.

Geophys., 147, 3, 483-496. 
Baskoutas I. 1998. Study of spatial distribution of coda Q with respect to the seismicity in central Greece. Bull Geol. Soc. Greece, 32/1 197-203.

Baskoutas I., Makropoulos K., Drakopoulos J. \& V. Kouskouna. 1989. Evaluation of seismic Q in central Greece from local events. Procced Int. Symp. on the Analysis of Seismicity and Seismic Risk, Bechyne Castle, Czechoslovakia, Sep. 4-9, 1989, 162-170.

Baskoutas I., Panopoulou G., Makropoulos K. \& J. Drakopoulos. 1992. Analysis of seismic coda by using seismic analog data of WSSN ATH station. $6^{\text {th }}$ Congress of the Hellenic Geological Society, Athens, (in Greek).

Baskoutas I., Stavrakakis G.N. \& I. S. Kalogeras. 1998. Q factor estimation from the aftershock sequence of the 13 May 1995 Kozani earthquake.J. Geodynamics, 26, 2-4, 367-374.

Baskoutas I., Panopoulou, G., \& Th. Rontoyanni. 2000. The seismic attenuation in two regions with different geological aspect. Boll. Geof. Theor. Appl., 41, 3, 233-242.

Hatzidimitriou P. M. 1993. Attenuation of coda waves in northern Greece. Pageoph., 140, 63-78.

Hatzidimitriou P.M. 1995. S-wave attenuation in the crust in northern Greece. Bull. Seism. Soc. Am. 85, 5, 1381-1387.

Havskov J., Malone S., McClurg D. \& Crosson R. 1989. Coda Q for the state of Washington, Bull. Seism. Soc. Am. 79, 4, 1024-1038.

Kovachev, S.A., Kuzin, I.P., Shoda, O.YU. and Soloviev, S.L. 1991. Attenuation of S waves in the lithosphere of the sea of Crete according to OBS observations. Phys. Earth Planet. Interiors, 69, 101-111.

Martin C. 1988. Geometrie et cinematique de la subduction Egeenne; structure en vitesse et en attenuation sous le Peloponnese. These Univ. Joseph Fourier, Grenoble.

Паvaүıшто́тоо

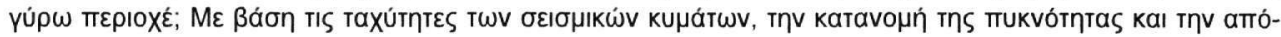

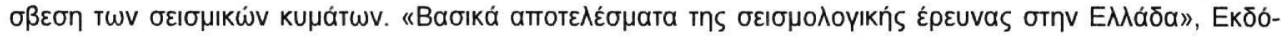

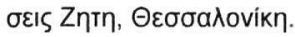

Papazachos, C.B. 1992. Anisotropic radiation modelling of macroseismic intensities for estimation of the attenuation structure of the upper crust in Greece. Pure Appl. Geophys., 138, 3, 445470.

Papazachos B. \& Papazachou C. 1997. The Earthquakes of Greece. Editions Ziti. Thessaloniki.

Papazachos B. Papaioannou Ch.A. Papazachos C. \& Savvaidis A.S. 1997. Atlas of isoseismal maps for strong $M \geq 5$ shallow $\mathrm{h}<60 \mathrm{~km}$ earthquakes in Greece and surrounding area 426 BC-1995. Geophys. Lab., Univ. of Thessaloniki, $4,187 \mathrm{pp}$.

Pérez A.C. 2000. Atenuación de ondas Coda en Grecia. Trabajo de Investigación dentro del programa de Doctorado de Geodesia, Geofísica y Meteorologia. Universidad Complutense de Madrid, 109 pp.

Pulli J.J. 1984. Attenuation of coda waves in New England Bull.Seism Soc.Am., 74, 4, 1149-1166.

Sato H. 1977a. Energy propagation including scattering effects single isotropic scattering aproximation. J. Phys. Earth, 25, 27-41.

Sato H. 1977b. Single isotropic scattering model including wave conversions simple theoretical model of the short period body wave propagation. J. Phys. Earth, 25, 163-176.

Tselentis G.A. Drakopoulos J.,\& Makropoulos C. 1988. On the frequency dependence of $Q$ in the Kalamata South Greece region as obtained from the analysis of the coda of the afthershocks of the Kalamata 1986 earthquake. Tectonophysics, 152, 157-159.

Tselentis G.A. 1993b. Depth dependent seismic attenuation in western Greece. Tectonophysics 225, 523-528.

Tselentis G.A. 1997. Evidence for stability in coda $Q$ associated with the Egion central Greece earthquake of 15 June 1995. Bull. Seism. Soc. Am., 87, 6, 1679-1684. 


\section{APPENDIX}

Table of Qc power low estimates in the territory Greek.

\begin{tabular}{|c|c|c|c|}
\hline $\begin{array}{l}\text { Lapse time or } \\
\text { distance }\end{array}$ & $Q_{c}=Q_{0} f^{n}$ & Region & Reference \\
\hline $10-20 \mathrm{sec}$ & $Q_{c}=33 f^{1.01}$ & North Greece & 1 \\
\hline $15-30 \mathrm{sec}$ & $Q_{c}=60 f^{0.79}$ & " & $"$ \\
\hline $20-45 \mathrm{sec}$ & $Q_{c}=89 f^{0.72}$ & $"$ & $"$ \\
\hline $30-60 \mathrm{sec}$ & $Q_{c}=94 f^{0.78}$ & $"$ & $"$ \\
\hline $50-100 \mathrm{sec}$ & $Q_{c}=128 f^{0.74}$ & $"$ & $"$ \\
\hline $20 \mathrm{sec}$ & $Q_{c}=47 f^{1.02}$ & Kozani-Grevena & 2 \\
\hline $40 \mathrm{sec}$ & $Q_{c}=80 f^{0.87}$ & $"$ & “ \\
\hline $60 \mathrm{sec}$ & $Q_{c}=100 f^{0.78}$ & $"$ & “ \\
\hline $80 \mathrm{sec}$ & $Q_{c}=124 f^{0.70}$ & $"$ & " \\
\hline $100 \mathrm{sec}$ & $Q_{c}=140 f^{0.71}$ & “ & " \\
\hline $10 \mathrm{sec}$ & $Q_{c}=29 f^{0.91}$ & Central Greece & 3 \\
\hline $20 \mathrm{sec}$ & $Q_{c}=45 f^{0.85}$ & $"$ & “ \\
\hline $30 \mathrm{sec}$ & $Q_{c}=62 f^{0.83}$ & " & " \\
\hline $40 \mathrm{sec}$ & $Q_{c}=80 f^{0.80}$ & “ & " \\
\hline $50 \mathrm{sec}$ & $Q_{c}=101 f^{0.73}$ & " & “ \\
\hline- & $Q_{f=1 H z}=182$ & Athens & 4 \\
\hline - & $Q_{c}=73 f^{0.95}$ & Peloponnesus & 5 \\
\hline $30 \mathrm{sec}$ & $Q_{c}=121 f^{0.72}$ & Gulf of Patras & 6 \\
\hline $50 \mathrm{sec}$ & $Q_{c}=141 f^{0.75}$ & “ & " \\
\hline $70 \mathrm{sec}$ & $Q_{c}=144 f^{0.81}$ & $"$ & “ \\
\hline $90 \mathrm{sec}$ & $Q_{c}=162 f^{0.83}$ & $"$ & “ \\
\hline \multirow[t]{2}{*}{$10-20 \mathrm{sec}$} & $Q_{c}=16 f^{1.1}$ & West part of Korinth & 7 \\
\hline & & Gulf & \\
\hline- & $Q_{\mathrm{C(f=4Hz)}}=183$ & Aegion & 8 \\
\hline- & $Q_{c(f=8 H z)}=270$ & “ & “ \\
\hline- & $Q_{c}=43 f^{0.81}$ & Kalamata & 9 \\
\hline $0-450 \mathrm{Km}$ & $Q_{\mathrm{f}=1 \mathrm{~Hz}}=350$ & Aegean sea & 10 \\
\hline $30-250 \mathrm{Km}$ & $Q_{\mathrm{f}=8 \mathrm{~Hz}}=200-300$ & NA part of Hellenic arc & 11 \\
\hline
\end{tabular}

(1) Hatzidimitriou, 1993, (2) Baskoutas et al., 1998, (3)Baskoutas, 1996, (4) Baskoutas et. al. 1992, (5) Martin 1988, (6) Tselentis 1993b, (7) Baskoutas etal., 1994, (8) Tselentis, 1997, (9) Tselentis et al., 1988b, (10) Papazachos C, 1992, (11) Kovachev et al., 1991. 